\title{
Whose express access? Assessing the equity implications of bus express routes in Montreal, Canada
}

\author{
James DeWeese \\ School of Urban Planning \\ McGill University \\ james.deweese@mail.mcgill.ca \\ Anastasia Belikow \\ School of Urban Planning \\ McGill University \\ anastasia.belikow@mail.mcgill.ca
}

\author{
Manuel Santana Palacios \\ School of Urban Planning \\ McGill University \\ manuel.santanapalacios@mcgill.ca
}

\author{
Ahmed El-Geneidy \\ School of Urban Planning \\ McGill University \\ ahmed.elgeneidy@mcgill.ca
}

\begin{abstract}
Express buses—characterized by limited stops and sometimes higher frequencies or priority traffic measures-offer a cost-effective and efficient way to boost service convenience and reliability for riders. This paper assesses how the accessibility benefits of express bus route policy are distributed in Montreal, Canada, while providing a pathway for public transportation agencies to assess their policies and plans. To isolate the impact of bus express routes, we use General Transit Speed Specification (GTFS) data, the Open Trip Planner multimodal routing engine, and the 2013 edition of Montreal's origin-destination survey to contrast travel time and accessibility at the trip and census-tract levels under two scenarios: one with the existing, complete network and the second a counterfactual scenario with no express bus routes. Our results indicate that bus express routes enable an overall increase in accessibility for the overall population. However, the accessibility benefits do not accrue evenly, as expected, but also tend to benefit a more significant number of higher incomes. This occurs despite the location of lowincome populations in some outlying areas of the city, which express bus routes are supposed to serve. This paper closes with policy recommendations that help planners balance economic, environmental, and equity goals, perhaps one of the most complex challenges they face nowadays.
\end{abstract}

\section{Introduction}

The adoption of bus express routes is a popular urban transportation policy in cities across the globe, but and has gained substantial attention from various public transport agencies in North American cities during the past decade (Tétreault \& El-Geneidy, 2010; Wu et al., 2018). Express bus routescharacterized by limited stops and sometimes higher frequencies, traffic priority measures, or a combination of all these approaches - offer policymakers an enticing opportunity to enhance service in a fast, affordable, and effective fashion than other alternatives such as urban rail transit. Since express bus services do not stop at every stop along a regular or traditional bus route, the former achieves the goal

Copyright 2022 James DeWeese, Manuel Santana Palacios, Anastasia Belikow \& Ahmed El-Geneidy http://dx.doi.org/10.5198/jtlu.2022.1879

ISSN: 1938-7849 | Licensed under the Creative Commons Attribution - Noncommercial License 4.0

The Journal of Transport and Land Use is the official journal of the World Society for Transport and Land Use (WSTLUR) and is published and sponsored by the University of Minnesota Center for Transportation Studies. 
of increasing bus operating speed, therefore improving urban mobility (Ercolano, 1984; Furth \& Day, 1985; Vuchic, 2005). Thus, by providing a viable faster alternative to traditional bus routes, express bus service is perceived as a viable substitute to automobiles and a cost-effective way to mitigate traffic congestion problems.

Express bus routes often follow the same design features. For instance, bus stop spacing can range from 800 to 1600 meters between stops (Conlon et al., 2001; Furth \& Day, 1985; Silverman et al., 1998) compared to regular bus services, where the spacing ranges between 200 to 600 meters (Ammons, 2001). Express bus services are usually implemented gradually and introduced as a pilot program on one or a few routes. In some cases, these services are tested running parallel to some of their regular routes, thus providing a point of comparison to users, policymakers, and scholars. Express bus services design has served as the blueprint for designing the celebrated bus rapid transit systems of Bogotá, Colombia, which inspired other cities to implement bus-only-lane express bus services to achieve high-capacity levels.

The growing interest in adopting express bus routes, at least in North America, has increased in part to the well-documented improvements in both service operations and customer satisfaction these generate (Conlon et al., 2001; Diab \& El-Geneidy, 2014; El-Geneidy \& Surprenant-Legault, 2010; Tétreault \& El-Geneidy, 2010). Despite the popularity of bus services around, there is surprisingly little empirical evidence assessing how the benefits provided by these interventions are distributed across the space and between income groups. Using Montreal's network of express buses as a case of study, this paper provides: [1] an assessment of how equitable the network of express bus services is in the city, and [2] a cost-efficient methodological pathway for transportation agencies to incorporate equity and accessibility assessments as part of their analytical tools.

Particularly in large North American urban areas and using the existing highway infrastructure, express buses services connect outlying neighbours and suburban areas with centrally located employment hubs. Thus, and in the North American context, these new services respond to historical patterns of urban development, in which suburbanites clog their cities' highway systems to commute to centrally located job hubs. Express routes are popular because these may provide commute time savings to residents switching from automobiles with potential benefits regarding mental and physical health associated with travel time savings and reductions in stress levels associated with driving (St-Louis et al., 2014). Moreover, reducing travel times for potential express bus route users may also translate into increased access to key destinations, including jobs often concentrated in one or a few clusters in large metro regions.

While on the one hand, express bus routes can improve overall mobility, access to opportunities, and overall well-being, on the other hand, these services may not benefit economically disadvantaged groups. During the past three decades, efforts to recapture lost transit markets - automobile users living in suburban areas- to reduce greenhouse gas emissions have collectively proven expensive and only marginally effective (Garrett \& Taylor, 1999; Manaugh \& El-Geneidy, 2012). Some of these efforts to attract lost markets have historically been at the expense of low-income minorities, many living in segregated urban centers, who also have fewer resources to buy and properly maintain an automobile (Garrett \& Taylor, 1999). The shift in policy objectives during the past two decades is at odds with the social role public transport has played in North America and has drawn the attention of activists and planners concerned with distributive justice - also referred to as equity. Nonetheless, these criticisms often overlook another already-documented trend that may change the distributional effects of investing in rapid or express transit services: many low-income households have relocated from central to outlying areas during the past three decades (Foth et al., 2013).

Considering the growing interests in promoting the adoption of principles of equity in planning practice, and the growing interests in express transit services, this study uses accessibility as an objective 
measure of the benefits accruing to users and would-be riders from express transit services using as a case of study Montreal's network of express bus services. More specifically, this paper answers: [1] How are the accessibility benefits from Montreal's express bus network distributed across income lines? [2] What can be learned from Montreal's express bus case of study to ease the adoption of accessibility and equity in contemporary transportation planning praxis across Canada and other parts of the globe?

\section{$2 \quad$ Literature review}

Despite the growing attention from policymakers and planers on express route service alternatives, there is significant scholarly attention to the various operational improvements these types of routes may provide; it appears that far less is known about how equitably the benefits of these enhanced services are enjoyed. While the large share of empirical work on express bus services and equity has focused on questions of fare structure, affordability, and geographical coverage (Brown, 2018; Wei et al., 2017), one performance measure that is gaining more traction in transportation justice and equity scholarship is the one of accessibility. Accessibility, the ease of reaching destinations (Hansen, 1959), is a comprehensive land use and transport performance measure (El-Geneidy \& Levinson, 2006; Geurs \& Van Wee, 2004) that can be used in evaluating the equitable distribution of transport resources in a region (van Wee $\&$ Geurs, 2011). Accessibility is a mode, time, and space-specific measure (Geurs \& van Eck, 2001).

Transport projects enhancing accessibility can help in generating economic prosperity and reduce social gaps when such service is distributed fairly in a region (Grengs, 2010; Jones \& Lucas, 2012). A more equally distributed, fast and reliable public transport system is expected to provide high levels of access to desired destinations (Foth et al., 2013) for an entire population. In contrast, uneven access to opportunities might prevent vulnerable groups from fully participating in society (Lucas \& Jones, 2012) or might push them to forced car ownership, accruing additional costs and, therefore, financial instability (Currie et al., 2009).

Accessibility has been extensively used to evaluate the network performance (Curtis \& Scheurer, 2015) and how equitable a transportation-land-use system is (El-Geneidy et al., 2016; Wachs \& Kumagai, 1973). Moreover, accessibility is frequently one of the primary tools discussed for measuring vertical or horizontal equity (Banister, 2018; Martens, 2016; van Wee \& Geurs, 2011). Horizontal equity is the notion of distributing services equally among all income groups, while vertical equity, often informed by Rawlsian views of distributive justice (Pereira et al., 2016), refers to the distribution of services to those who need them the most. Thus, when looking at public transit, vertical equity provides a fairer assessment of the system, as some groups are more in need of this type of public good than others (Krumholz \& Forester, 1990). A large share of this scholarship relies on cross-sectional accessibility analyses, which according to Wachs and Kumagai (1973), constitute an important social report for a city or urban region.

However, only until the past few years, scholars have capitalized on data that captures employment spatial data and changes in public transit supply over time and counterfactual thinking to assess the distributional effects of such changes in job accessibility. Most of this emerging body of research examines bus rapid transit, which evolves from the concept of express bus services. For instance, Pereira et al. (2019), operationalizing the concept of accessibility, found that Rio de Janeiro's BRT enables gains in access to jobs that are skewed towards middle- and high-income areas. Oviedo et al. (2019) obtain similar findings in their empirical accessibility analysis of Lima's BRT. Other scholars have employed the concept of accessibility to assess the impact on access to employment from other public transportation modes, finding opposite results. For instance, Fan et al. (2012) used the concept to study how a suburban light rail transit line in the Twin Cities in Minnesota changes the geography of access to low-wage 
jobs. Their findings suggests that the project had positive impacts when considered principles of equity and access to employment.

Accessibility can be operationalized or measured, in numerous ways, without agreement on what planners should use. In this paper, we employ a cumulative-opportunities approach, which counts the number of destinations that can be reached within a specific threshold of travel time by a specific mode (Geurs \& Van Wee, 2004; Handy \& Niemeier, 1997). This is one of the most commonly used measures in transport planning and practice due to its simplicity in communication (Boisjoly \& El-Geneidy, 2017) and theoretical soundness. Cumulative-opportunities measures are highly correlated to other indicators that closely follow travel behaviour, such as gravity-based measures (El-Geneidy \& Levinson, 2006), especially at the levels near the mean travel times in a region.

In cases with no public transport data, other scholars have relied on self-reported travel data to assess the role of express bus services in reducing commute times. For instance, Palacios and Rayle (2021) employed data from a retrospect survey to estimate BRT systems' distributional effect that capitalized on the advantage of express bus services on commute time savings across socioeconomic lines. They found that in Cape Town's BRT, the express bus services connecting outlying townships with the city center make the BRT reduce gaps in commute times between Black and non-Black population groups. Other scholars have employed multiple cross-sections of self-reported travel information, including trip origin and destination, travel times, and modes, to understand how interventions in public transport systems can reduce gaps in commute times.

Our study contributes to the literature in the following three ways. First, we compare the marginal gains in precision when matching low-income workers with low incomes versus estimation accessibility considering the total job market using a counterfactual thinking framework - that is, what would have happened had the intervention not occurred? - and provide step-by-step methodological recommendations. Second, we tested how useful it is to use the popular side-by-side with-and-without project mapping approach to assess the success of improving a public transport network and provide additional descriptive analyses that may help planners better to understand the potential impact of projects in question. Finally, our work takes advantage of origin-destination travel surveys, which, paired with monetary valuations of time, provide another point of view to understand how benefits from transportation are distributed.

\section{Study context}

Montreal is Canada's second-largest city, with a metropolitan population of over four million residents (Statistics Canada, 2016a). The city of Montreal boasts two million residents, who rely on the Société de Transport de Montréal (STM) as their primary public transport provider for bus and metro systems. This is in addition to a network of commuter trains and buses operated by EXO serving parts of Montreal and the outer suburbs. As the origin-destination survey suggests, public transport mode share is around 19\% during the morning peak period in 2013 for the Montreal metropolitan region and 36\% for the city of Montreal. The STM operates a network of 219 bus lines, including 33 express bus routes covering the city of Montreal and a network of four rubber-tired metro lines concentrating in the center of the city and well connected with the bus services. Figure 1 shows the city of Montreal with the express bus network in dark grey and regular buses in light grey, and the Metro and commuter rail systems in red and blue, respectively. 


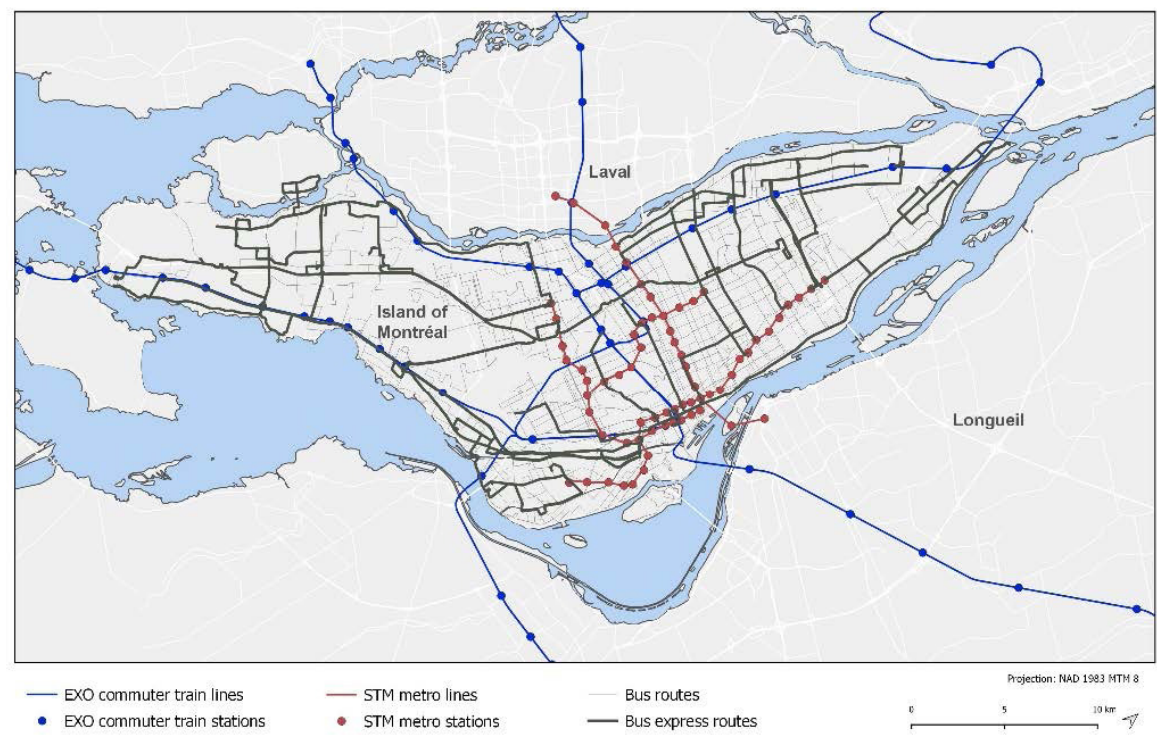

Figure 1. Transportation system in Montreal

\section{$4 \quad$ Data and methods}

To evaluate the impact of the express bus service network in Montreal, we built two public transport system network scenarios in Open Trip Planner (OTP), a previously validated tool for generating travel times using the Generalized Transit Feed Specification (GTFS) (Hillsman \& Barbeau, 2011). The first scenario included the existing bus and urban rail network in February 2020. The second one constituted our counterfactual representing the hypothetical scenario with no express routes -- all other things are equal. Two travel time matrixes were generated measuring the travel time between every census tract centroid, accounting for walking and waiting times. Travel times were calculated at 10-minute intervals from 8:00 a.m. to 8:30 a.m. and then averaged to account for fluctuations in service frequency during the morning rush hour. These calculations were done with data corresponding to Wednesday, Feb. 12, 2020.

The travel time matrixes generated with OTP were then used to estimate cumulative- opportunities measures of accessibility using $R$ programing language. The number of jobs reached within 45 minutes of travel time from any centroid on the island to all jobs in the region was estimated for the entire network and counterfactual scenario. A subsequent accessibility estimation was generated to count the number of low-income jobs reached within our target commute time threshold. Low-income jobs are defined as jobs making an annual salary below $\$ 30,000$. The number of jobs in each census tract was obtained from Census WorkFlows (Statistics Canada, 2016b). Then, using a series of maps showing cumulative opportunities measures of accessibility by public transport, we compared the existing network with a counterfactual scenario with no express routes. We also demonstrated these differences in maps, highlighting the spatial distribution of census tracts within the lowest $30 \%$ of median income.

We selected 45 minutes of travel time as the commute time threshold for this analysis because it closely aligns with Montreal's average public transport commuting time (Statistics Canada, 2016c). The use of morning peak only data could impose some marginal biases too. However, these biases are not considered a problem since empirical evidence indicates that the morning peak is representative of the relative accessibility over the day and, therefore, appropriate for this type of analysis (Boisjoly \& El- 
Geneidy, 2016).

We also selected census tracts as the unit of analysis in this study since the jobs data employed were already aggregated into that geographical subdivision. Though the use of census tract geography as the unit of analysis can impose some biases in the calculations of accessibility (Wessel \& Farber, 2019) due to the location of the centroid in census tracts with large areas, such bias has shown to be minimal because census tracts are relatively small and the walking-transit network dense enough. Evidence indicates that the differences between using finer spatial fidelity generate only marginal improvements in the estimations (Cui et al., 2019).

Following the accessibility analyses, a comparison of travel time savings associated with express bus routes is conducted. This comparison used detailed trip-level data obtained from the 2013 edition of Montreal's origin-destination survey, the most recent publicly available version (AMT, 2013). The OD survey has been conducted every five years since 1970, collecting information from a random sample of $5 \%$ of the Montreal metropolitan region population. The survey collects travel habits over the preceding 24-hour weekday period, in addition to socioeconomic and household characteristics, such as annual household income level. Under special agreement with AMT, the regional transportation authority responsible for conducting the OD survey in 2013, we obtained the detailed bus service used by everyone in the survey, enabling us to isolate express bus users from others.

Using the 2013 OD survey, total travel times (including walking, waiting, and in-vehicle times) were calculated for each public transport user residing in Montreal under both scenarios (entire network and counterfactual) to estimate accessibility to jobs associated with the deployment of the express bus services. The availability of income groups at the household level from the OD survey enabled us to uncover some of the equity implications of express services and calculate the total time saved for each income group. Finally, we mapped in QGIS our results, overlaying them with lower-income census tracts, which we defined as those tracts having the lowest 30 percentile of. This cartographic description aimed to highlight the equity implications of express bus routes regarding the spatial distribution of travel-time savings.

\section{$5 \quad$ Results}

\subsection{Accessibility analysis}

\subsubsection{The spatial distribution of access to jobs}

Figure 2 shows access to employment by public transport in the city of Montreal. The map on the top displays access to employment with the complete public transport network, while the map on the bottom shows our counterfactual scenario (without express routes). Accessibility measures are normalized to enable comparisons. The lowest accessibility values, in blue colors in both maps, are primarily located on the two far edges from the center of the city at the city's eastern and western city sections. The areas experiencing high accessibility, in red, are located in the heart of the city around the Metro lines and near the downtown area.

The most significant differences between the two maps presented in Figure 2 appear to be that the map showing accessibility with the entire public transport system has a lower number of low-access zone (in blue) categories and more areas in the highest (in red) category than the counterfactual scenario map. This first qualitative cartographic comparison suggests that the network of express buses impacts 
access to employment in several places throughout the island. In terms of the equity implications of the transit services, it can be noticed that many of the census tracts with median incomes belonging to the lowest 30 percentile have access to plenty of employment opportunities, with several of them belonging to the highest accessibility category, with an exception to those located in the northeast section of the city where they are primarily in the lower category.
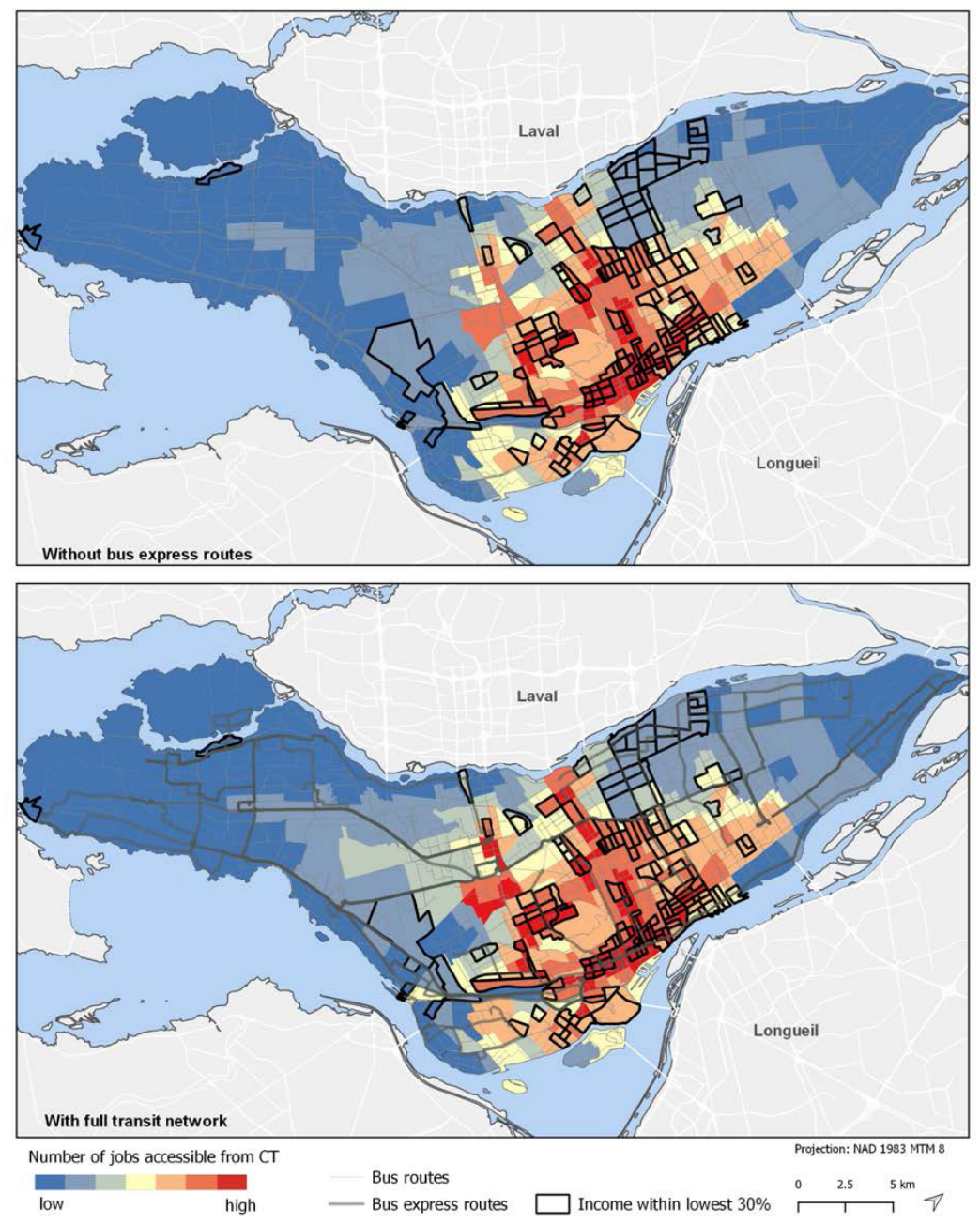

Figure 2. Accessibility to employment opportunities by census tract

Figure 3 provides a socioeconomic perspective into accessibility to employment by showing accessibility to low-wage jobs in Montreal. The number of low-wage jobs in Montreal is approximately 1/3 of the number of total jobs in the region. To enable comparison with previous maps, the categories used in this map are normalized on a low-to-high, within-group scale to enable comparisons to the previous maps. With these adjusted categories, we can see that the number of census tracts with high accessibility levels is lower than in the previous figure, suggesting more concentration of these employment opportunities, regardless of the effect of bus express routes. Overall, however, the spatial distribution of lower-income job accessibility does not seem to differ significantly from that of all jobs. Residents of census tracts located in the center, North and North-East areas of the island have abundant access to jobs with annual salaries below $\$ 30,000$. Many of the high-access census tracts also belong to the island's bottom $30 \%$ in terms of income. While the cartographic comparison has provided some insights, the 
quantitative differences between the two maps, and the population group of interests, are too difficult to infer from the two visualizations, even with the ample color-ramp range used. For this reason, our study requires additional analyses, which we present in the following sections of the paper.
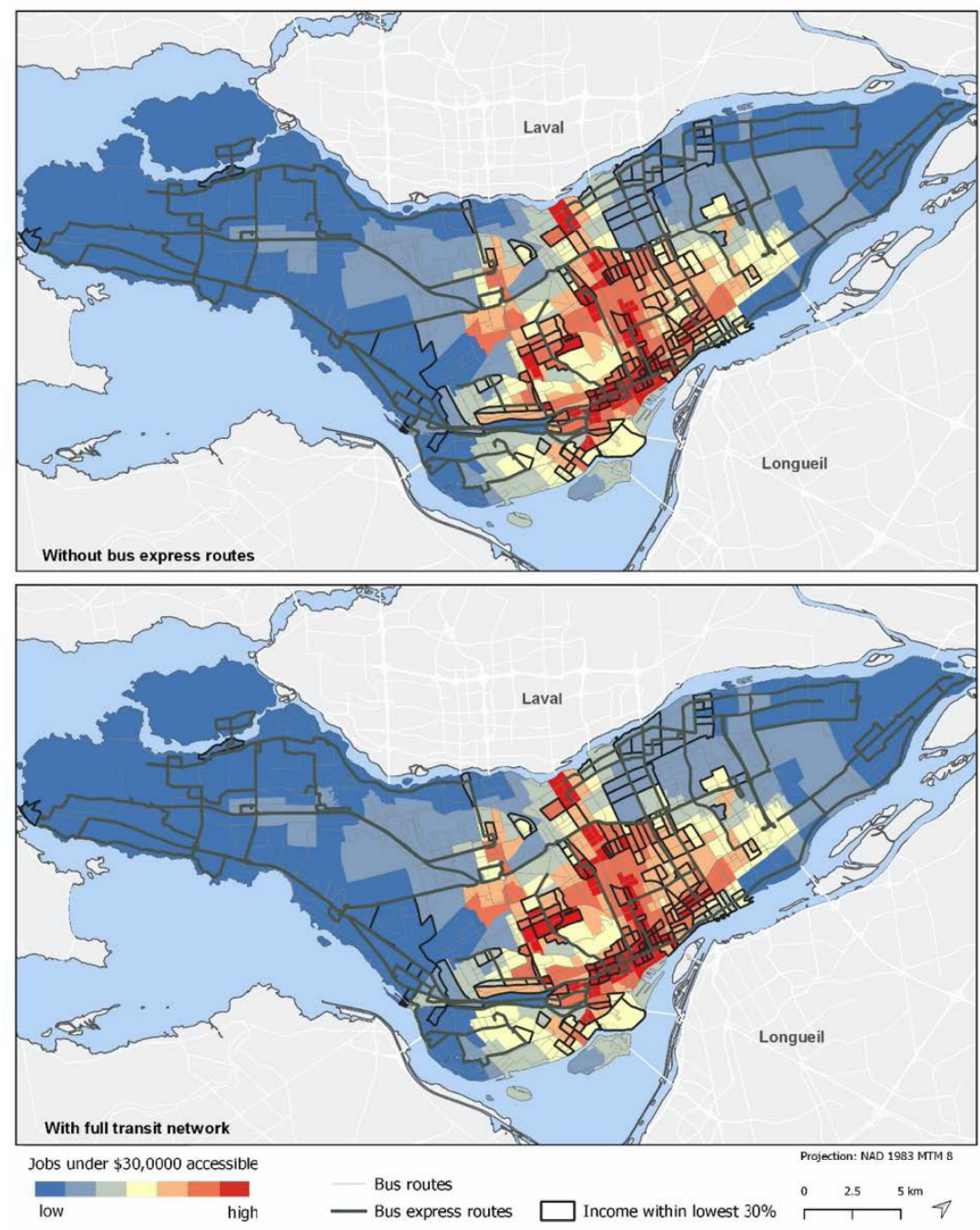

Figure 3. Accessibility to low-wage employment by census tract

\subsubsection{The spatial distribution of improvements in accessibility attributable to bus express routes}

Figure 4 shows the percentage difference between the jobs accessible in 45 minutes of travel time by public transport with complete network scenario and the counterfactual (with no express bus routes). This was calculated by dividing the difference between the number of jobs accessible in 45 minutes under each network scenario (without and with bus express routes) by the total amount of jobs accessible using the entire public transport network. Dark blue areas, identified as having a "low" percentage change, correspond to census tracts in which bus express routes improve accessibility by less than $6 \%$. In comparison, reds indicate changes ranging from $31 \%$ to $75 \%$. Census tracts with lower overall accessibility to jobs located in the extreme ends of the island (as shown in Figure 2 and Figure 3) seem to benefit the most from bus express service, especially in the west and northeast sections of the island of Montreal. Bus express routes do not contribute much to the number of jobs that residents of lowerincome census tracts can reach, primarily blue areas with thick black borders on the map, except those in the northeast sections. The percentage change in access to all jobs and the percentage change in 
lower-income jobs are relatively minor. The latter simply suggests that the geographical distribution of low-income jobs in Montreal is not that different from the one of all jobs.
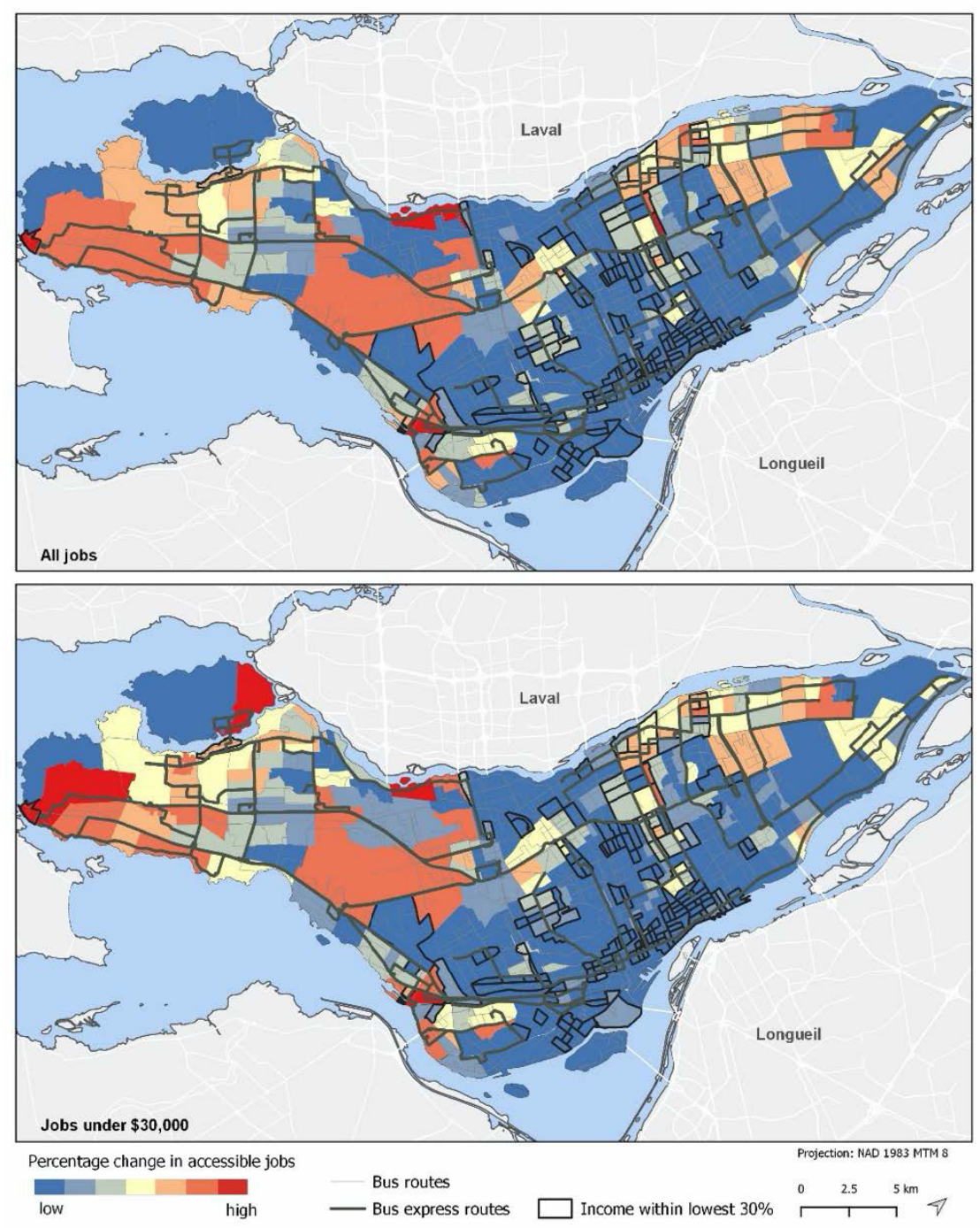

Figure 4. Proportion of jobs accessible explained by bus express routes

\subsubsection{The sociodemographic distribution of bus express route accessibility improvements}

To further explore the distributional effect of bus express routes, the median income and percentage change in access to employment opportunities were contrasted in Figure 5. The figure on the left-hand side shows the relation between median income and percentage change in access to all job opportunities. In contrast, the figure at the right shows the effect of bus express routes on access to employment with salaries below $\$ 30,000$.

In line with observations made in the previous figures, bus express routes seem to suggest that the intervention in questions is slightly regressive. This assertion is corroborated with the trend line presented in Figure 5, which exhibits a positive slope in both scatterplots showcasing the change in jobs accessible enabled by the intervention with the median income of each census tract in the city. It is 
important to note that while these types of data visualization are often employed to test statistical associations between two variables, we use them as an exploratory mechanism to identify clusters of low and high impact by income and examine whether there is any apparent trend. Figure 5 also suggests minor differences between access to all types of employment and low-income employment, with the slope being slightly more pronounced in the latter.

To improve comparability with the figures analyzed in the previous section, census tracts with median incomes belonging to the lowest 30 percentile are depicted in black instead of blue. As can be seen, there is significant variation in the effect of express routes on these areas. There are also clear outliers, mainly of very high-income locations that experienced no change in the number of accessible jobs. This figure helps summarize what is seen in the previous maps. Overall, census tracts with higher incomes had a higher percentage change in the number of employment opportunities reachable due to bus express routes.
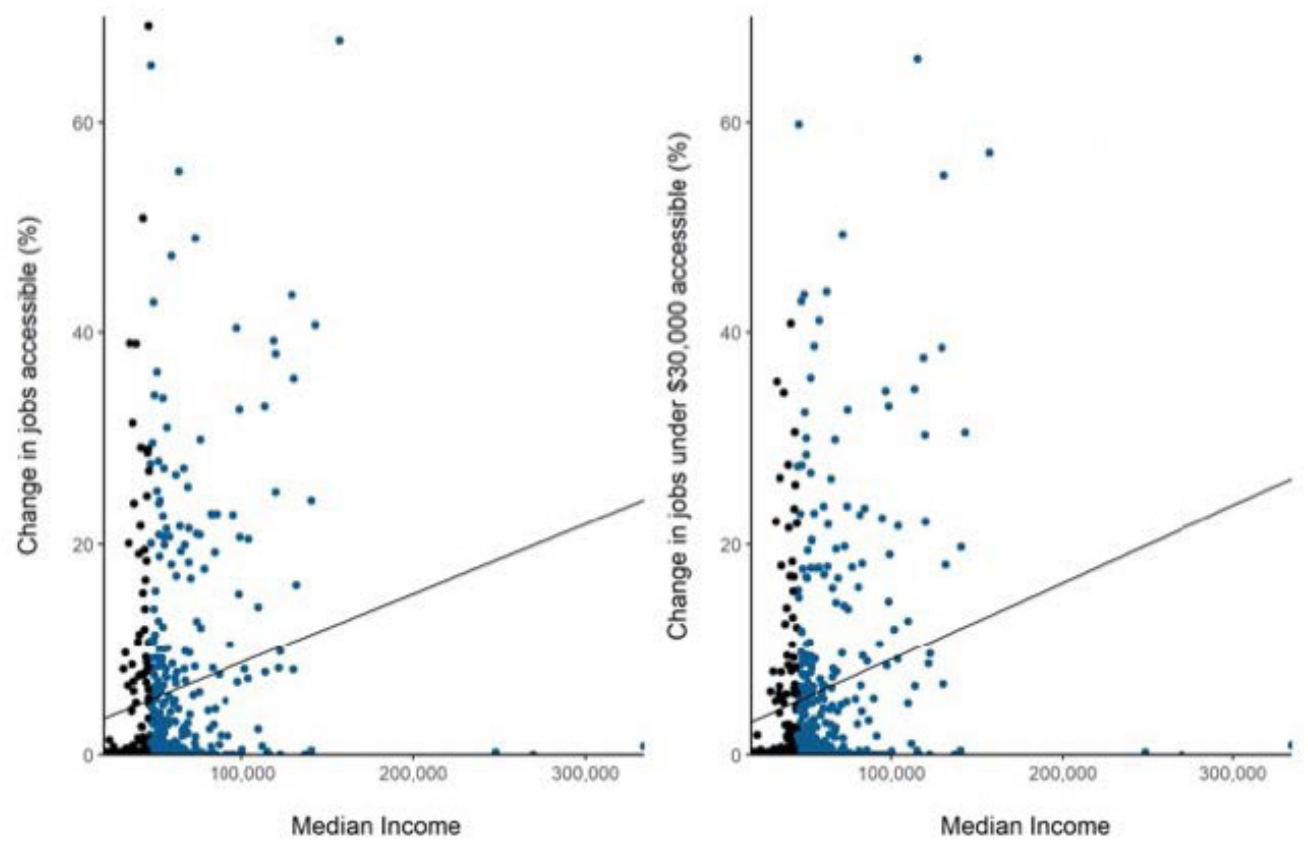

Figure 5. Median income and bus express routes' effect on accessibility

Observing the areas with the highest percentage change in accessibility to all jobs due to express routes' presence can help reveal the impacts of the express routes on overall levels of accessibility. Table 1 shows a tendency for the areas that benefit the most from bus express routes to have higher median income levels. Census tracts belonging to the top $5 \%$ in terms of accessibility gains from express services were the richest on average. The table confirms that bus express routes are beneficial, in terms of access to employment opportunities, for people beginning their trips in upper-income census tracts. 
Table 1. Census tracts by change in accessibility (percentiles)

\begin{tabular}{cc}
\hline Within top $5 \%$ & Rest of values $(95 \%)$ \\
\hline$\$ 80,299$ & $\$ 56,450$ \\
\hline Within top $10 \%$ & Rest of values $(90 \%)$ \\
\hline$\$ 71,057$ & $\$ 56,141$ \\
\hline Within top $20 \%$ & Rest of values $(80 \%)$ \\
\hline$\$ 67,782$ & $\$ 55,137$ \\
\hline
\end{tabular}

\subsubsection{Using self-reported travel time savings: toward a person-based approach}

The findings show the equity implications of bus express routes at the census tract level so far. However, there can be substantial variation within the same census tract in terms of socioeconomic characteristics. Data from the Montreal origin and destination travel survey allows us to develop an alternative way to understand how accessibility gains relate to individual transit users. It provides information at the trip level. In other words, it allows us to quantify the amount of time saved by individuals currently using the express buses, as the OD survey includes detailed information regarding which bus service a commuter uses.

Table 2 shows the average travel time savings for individuals using bus express routes and their household income. In line with previous results, users most benefiting from these routes belong to upper-middle-income households. For instance, individuals belonging to households earning salaries between $\$ 90,000$ to $\$ 149,000$ average $22 \%$ more minutes saved than the population mean and $39 \%$ more than individuals belonging to the $\$ 30,000$ to $\$ 59,999$ income bracket.

Table 2. Time savings for each trip by income levels

\begin{tabular}{lcc}
\hline \multicolumn{1}{c}{ Income } & Average savings $(\mathrm{min})$ & Aggregated savings (hours) \\
\hline Less than $\$ 30,000$ & 5.6 & 684 \\
$\$ 30,000$ to $\$ 59,999$ & 5.1 & 940 \\
$\$ 60,000$ to $\$ 89,999$ & 5.0 & 735 \\
$\$ 90,000$ to $\$ 119,999$ & 7.2 & 869 \\
$\$ 120,000$ to $\$ 149,999$ & 7.1 & 235 \\
$\$ 150,000$ and more & 6.1 & 272 \\
All income levels & 5.8 & 3734 \\
\hline
\end{tabular}

In terms of the spatial distribution of these savings, Figure 6 shows total travel time savings aggregated by trip origin at the census tract level of analysis, summing the total time savings in one-way trips leaving the census tract in a day. The top map shows aggregated travel time savings for individuals with household earnings below $\$ 30,000$, while the second map shows the savings for all trips made in a day. Similarly to Fig.4, this shows that most gains from bus express routes concentrate on the western half of the island. Some census tracts closer to the downtown area also benefit from the express service. Savings for trips made by individuals within lower-income brackets were sometimes significant, especially those living at the west and east ends of the island, totalling more than 20 hours of travel time savings per day among all individuals leaving these census tracts by express routes in a day. 

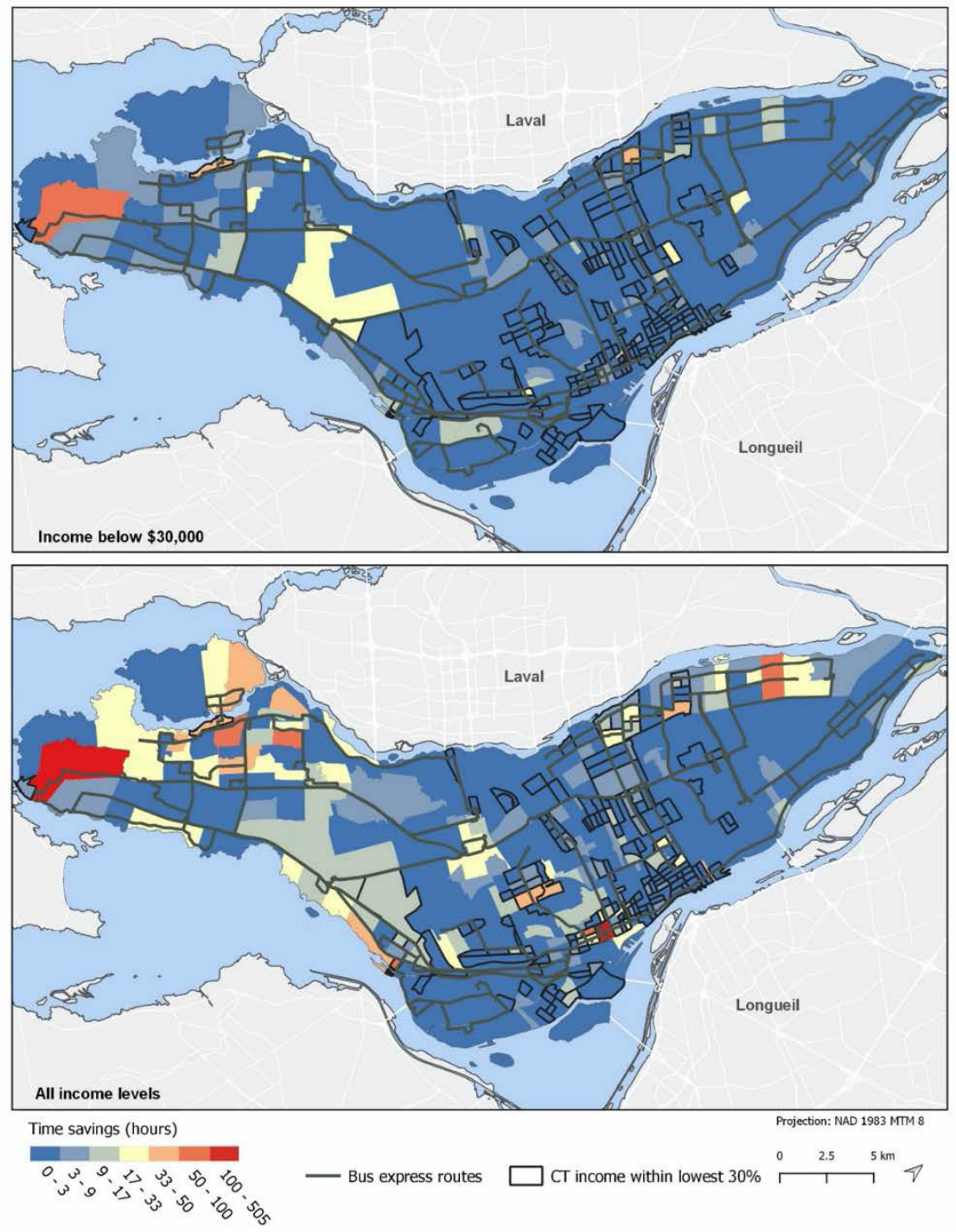

Figure 6. Aggregated travel time savings

\section{Conclusions}

Overall, bus express routes provide sizeable benefits to Montreal residents. These express bus routes improve access to employment opportunities and reduce travel times significantly for a large proportion of the population. In fact, during the morning commute alone, express buses account for 620 hours of commute time saved throughout the city, suggesting the intervention is performing at least to improve mobility in the city. When considering half a minimum wage as the cost of time spent on commutes (Anas, 2020), bus express routes account for yearly savings equivalent to $\$ 2,101,924$, underscoring the economic value of the benefits. Looking at the overall time savings stemming from all types of trips made to the city, the equivalent comes to 3,734 hours saved daily or $\$ 6,236,713$ in a year (without weekends and holidays). While these results are only positive, another completely different and yet equally important matter is whether the benefits are skewed towards lower-income populations, who 
often depend on public transportation.

Our stepwise descriptive accessibility analysis indicates that, at least in Montreal, where this case of study is based, accessibility benefits from express bus services are skewed towards higher income population groups. These findings emerged from a series of maps and spatially agnostic visualizations, which together prove to be a powerful tool to understand the distributional impact of investments in the public. Our method further provides another point of view using data and methods more common in contemporary planning practice: estimating travel times reductions and assigning a monetary value to time. Our findings indicate that the richest bus express users enjoy the biggest travel time gains, with users with annual household earnings between $\$ 90,000$ and $\$ 120,00$ saving more than 7 minutes on each trip. Also, users living in census tracts within the top decile in terms of accessibility gains earned, on average, almost $\$ 24,000$ more than the rest. While people with earnings below $\$ 30,000$ do, in some cases, get substantial travel time savings due to express routes, these services do not seem to lead to a considerable increase in access to jobs with wages below $\$ 30,000$, except in some areas on the western half of the city.

In other words, our findings indicate that bus express routes in Montreal have a slightly regressive effect when comparing effects on different income groups. However, this means that bus express routes provide an attractive option for higher-income users living further away from the city core and living in areas with fewer public transit options. As these users could be using cars to commute instead, there might be a positive effect of bus express routes on the environment and congestion levels. However, a focus on improving ridership levels amongst upper income may skew transit investments away from more vulnerable citizens, who depend on public transit the most, unless some of these investments also reach low-income populations living in outlying areas. In such a way, planners could balance environmental and equity goals by identifying the social makeup of the neighbourhoods these routes will serve.

It is essential to mention that our research only focuses on the distributional effects of express routes in Montreal on accessibility to employment. Further research should be carried out to understand whether differences in accessibility gains from bus express routes stem from spatial coverage objectives or institutional biases in planning. Future research should examine how the concept of accessibility and equity can be better incorporated into travel demand modelling practice, better balancing goals of efficiency and equity. Another important aspect we do not cover in this piece consists of the differences of using static or real-time data representing public transport operations in GTFS format. Future research should also examine methodological approaches to reconcile in-real time bus operations with timetables, acknowledging the balance needed between precision and simplicity. Hence, findings are more likely to use by transportation planners in practice.

Our results suggest that, as policymakers pursue new bus express routes as an attractive and costeffective option to improve system efficiency, more explicit and nuanced consideration of equity should play a role in system design. Over the coming years, Montreal public transport operators and policymakers will also find it necessary to adjust existing bus express routes. For example, bus express routes will face competition from the Réseau express métropolitain (REM), a \$6 billion light-rail project currently under construction in Montreal. Existing bus express routes may lose some of their attractiveness vis-àvis new rail options, forcing planners to re-evaluate specific routes to align them with new REM stations better. The necessary reconsideration provides a valuable opportunity to target adjustments in express bus service to more wisely to the new transport network to keep improving accessibility levels, especially for lower-income areas that are not expected to be directly served or benefited by the REM. However, as bus express routes evolve, it is clear that any decision-making process regarding this transport option needs to consider equity measures. This paper shows that accessibility analyses are a well-suited tool for such types of evaluation. 


\section{Acknowledgements}

Funding for this report comes from Natural Sciences and Engineering Research Council of Canada (NSERC) RGPIN-2018-04501. We would also like to thank Mr. Daniel Bergeron from ARTM for providing us with access to the detailed Montreal OD-survey data. We would like to thank the anonymous reviewers for their feedback on the earlier versions of the manuscripts as they helped in making the paper more clear and stronger. 


\section{References}

Ammons, D. N. (2001). Municipal benchmarks: Assessing local performance and establishing community standards (2nd ed.). Thousand Oaks, CA: Sage Publications.

AMT. (2013). Montreal metropolitan area origin destination survey 2013. Montreal: Montreal Transit Company.

Anas, A. (2020). The cost of congestion and the benefits of congestion pricing: A general equilibrium analysis. Transportation Research Part B: Methodological, 136, 110-137.

Banister, D. (2018). Inequality in transport. Oxford, UK: Alexandrine Press.

Boisjoly, G., \& El-Geneidy, A. (2016). Daily fluctuations in transit and job availability: A comparative assessment of time-sensitive accessibility measures. Journal of Transport Geography, 52, 73-81. https://doi.org/10.1016/j.jtrangeo.2016.03.004

Boisjoly, G., \& El-Geneidy, A. (2017). The insider: A planners' perspective on accessibility. Journal of Transport Geography, 64, 33-43. https://doi.org/10.1016/j.jtrangeo.2017.08.006

Brown, A. E. (2018). Fair fares? How flat and variable fares affect transit equity in Los Angeles. Case Studies on Transport Policy, 6(4), 765-773. https://doi.10.1016/j.cstp.2018.09.011

Conlon, M., Foote, P., O'Malley, K., \& Stuart, D. (2001). Successful arterial street limited-stop express bus service in Chicago. Transportation Research Record, 1760, 74-80.

Cui, B., Grisé, E., Stewart, A., \& El-Geneidy, A. (2019). Measuring the added effectiveness of using detailed spatial and temporal data in generating accessibility measures. Transport Findings. https:// doi.org/10.32866/9736

Currie, G., Richardson, T., Smyth, P., Vella-Brodrick, D., Hine, J., Lucas, K., . . Stanley, J. (2009). Investigating links between transport disadvantage, social exclusion and well-being in MelbournePreliminary results. Transport Policy, 16, 97-105. https://doi.10.1016/j.tranpol.2009.02.002

Curtis, C., \& Scheurer, J. (2015). Performance measures for public transport accessibility: Learning from international practice. Journal of Transport and Land Use, 10(1) 93-118. https:/doi.10.5198/ jtlu.2015.683

Diab, E., \& El-Geneidy, A. (2014). Transitory optimism: Changes in passenger perception following bus service improvement over time. Transportation Research Record, 2415, 97-106.

El-Geneidy, A., \& Levinson, D. (2006). Access to destinations: Development of accessibility measures. St. Paul, MN: Minnesota Department of Transportation.

El-Geneidy, A., Levinson, D., Diab, E., Boisjoly, G., Verbich, D., \& Loong, C. ( 2016). The cost of equity: Assessing accessibility by transit and social disparity using total travel cost. Transportation Research Part A: Policy and Practice, 91, 302-316.

El-Geneidy, A., \& Surprenant-Legault, J. (2010). Limited-stop bus service: An evaluation of an implementation strategy. Public Transport: Planning and Operation, 2(4), 291-306.

Ercolano, J. M. (1984). Limited-stop bus operations: An evaluation. Transportation Research Record, 994, 24-29.

Fan, Y., Guthrie, A. E., \& Levinson, D. M. (2012). Impact of light rail implementation on labor market accessibility: A transportation equity perspective. Journal of Transport and Land Use, 5(3), 28-349. https://doi.10.5198/jtlu.v5i3.240

Foth, N., Manaugh, K., \& El-Geneidy, A. (2013). Towards equitable transit: Examining transit accessibility and social need in Toronto, Canada, 1996-2006. Journal of Transport Geography, 29, 1-10.

Furth, P., \& Day, B. (1985). Transit routing and scheduling strategies for heavy demand corridors. Transportation Research Record, 1011, 23-26.

Garrett, M., \& Taylor, B. (1999). Reconsidering social equity in public transit. Berkeley Planning Jour- 
nal, 12(1), 6-27.

Geurs, K., \& van Eck, R. (2001). Accessibility measures: Review and applications. Evaluation of accessibility impacts of land-use transportation scenarios, and related social and economic impact. Utrecht, the Netherlands: National Institute for Public Health and the Enviornment.

Geurs, K., \& van Wee, B. (2004). Accessibility evaluation of land-use and transport strategies: Review and research directions. Journal of Transport Geography, 12(2), 127-140.

Grengs, J. (2010). Job accessibility and the modal mismatch in Detroit. Journal of Transport Geography, $18(1), 42-54$.

Handy, S., \& Niemeier, D. (1997). Measuring accessibility: An exploration of issues and alternatives. Environment and Planning A, 29, 1175-1194.

Hansen, W. G. (1959). How accessibility shapes land use. Journal of the American Institute of Planners, 25(2), 73-76.

Hillsman, E., \& Barbeau, S. (2011). Enabling cost-effective multimodal trip planners through open transit data. Tampa, FL: University of South Florida, Center for Urban Transportation Research.

Jones, P., \& Lucas, K. (2012). The social consequences of transport decision-making: Clarifying concepts, synthesizing knowledge and assessing implications. Journal of Transport Geography, 21, 4-16.

Krumholz, N., \& Forester, J. (1990). Making equity in planning work: Leadership in the public sector. Philadelphia: Temple University Press.

Lucas, K., \& Jones, P. (2012). Social impacts and equity issues in transport: An introduction. Journal of Transport Geography, 21, 1-3. https://doi.org/10.1016/j.jtrangeo.2012.01.032

Manaugh, K., \& El- Geneidy, A. (2012). Who benefits from new transportation infrastructure? Using accessibility measures to evaluate social equity in public transport provision. In K. T. Guers, K. J. Krizek, \& A. Reggiani (Eds.), Accessibility analysis and transport planning (pp. 211-227). Cheltenham, UK: Edward Elgar.

Martens, K. (2016). Transport justice: Designing fair transportation systems. New York: Routledge.

Oviedo, D., Scholl, L., Innao, M., \& Pedraza, L. (2019). Do bus rapid transit systems improve accessibility to job opportunities for the poor? The case of Lima, Peru. Sustainability, 11(10), 2795. https:// doi.10.3390/su11102795

Pereira, R. H. M., Banister, D., Schwanen, T., \& Wessel, N. (2019). Distributional effects of transport policies on inequalities in access to opportunities in Rio de Janeiro. Journal of Transport and Land Use, 12(1), 741-764. https://doi.10.5198/jtlu.2019.1523

Pereira, R. H. M., Schwanen, T., \& Banister, D. (2016). Distributive justice and equity in transportation. Transport Reviews, 37(2), 170-191. https://doi.10.1080/01441647.2016.1257660

Santana Palacios, M., \& Rayle, L. (2021). Shorter commutes, but for whom? Comparing the distributional effects of bus rapid transit on commute times in Cape Town, South Africa, and Barranquilla, Colombia. Journal of Transport and Land Use, 14(1), 647-667. https://doi.org/10.5198/ jtlu.2021.1907

Silverman, N., Orosz, T., \& Zicklin, A. (1998). Practitioner's forum: Limited-stop bus service at New York City Transit. Journal of Transportation Engineering, 124(6), 503-509.

St-Louis, E., Manaugh, K., van Lierop, D., \& El-Geneidy, A. (2014). The happy commuter: A comparison of commuter satisfaction across modes. Transportation Research Part F: Traffic Psychology and Behavior, 26, 160-170. https://doi.10.1016/j.trf.2014.07.004

Statistics Canada. (2016a). 2016 Census of Canada. Ottawa: Statistics Canada.

Statistics Canada. (2016b). Employed labor force 15 years and over having a usual place of work by income groups in 2015 (27) and mode of transportation (20), for commuting flow for Canada, Alberta, its census metropolitan areas, its tracted census agglomerations, its census tracts, elsewhere 
in Alberta and elsewhere in Canada, 2016 census - 25\% sample data. Ottawa: Statistics Canada.

Statistics Canada. (2016c). Main mode of commuting (20), commuting duration (7), time leaving for work (7), sex (3) and age (11B) for the employed labor force aged 15 years and over having a usual place of work or no fixed workplace address, in private households of Canada, provinces and territories, census metropolitan areas and census agglomerations. Ottawa: Statistics Canada.

Tétreault, P., \& El-Geneidy, A. (2010). Estimating bus run times for new limited-stop service using archived AVL and APC data. Transportation Research: Part A, 44(6), 390-402.

van Wee, B., \& Geurs, K. (2011). Discussing equity and social exclusion in accessibility evaluations. European Journal of Transport and Infrastructure Research, 11(4), 350-367.

Vuchic, V. (2005). Urban transit: Operations, planning and economics. Indianapolis: John Wiley and Sons.

Wachs, M., \& Kumagai, T. G. (1973). Physical accessibility as a social indicator. Socio-Economic Planning Sciences, 7(5), 437-456. https://doi.10.1016/0038-0121(73)90041-4

Wei, R., Liu, X., Mu, Y., Wang, L., Golub, A., \& Farber, S. (2017). Evaluating public transit services for operational efficiency and access equity. Journal of Transport Geography, 65, 70-79. https:// doi.10.1016/j.jtrangeo.2017.10.010

Wessel, N., \& Farber, S. (2019). On the accuracy of schedule-based GTFS for measuring accessibility. Journal of Transport and Land Use, 12(1), 475-500. https://doi.10.5198/jtlu.2019.1502

Wu, X., Cao, J., \& Huting, J. (2018). Using three-factor theory to identify improvement priorities for express and local bus services: An application of regression with dummy variables in the Twin Cities. Transportation Research Part A: Policy and Practice, 113, 184-196. https://doi.org/10.1016/j. tra.2018.04.003 